\title{
Educational Intervention to Improve Breast Self- Examination Practice among Women: Evidence-Based-Practice
}

\author{
Jinnat Rehena ${ }^{1}$, Md Anwar Hossain ${ }^{2 *}$ and Musammat Sultana Razia ${ }^{3}$ \\ ${ }^{1}$ Master of Science in Nursing (Adult and Elderly Health Nursing), Mahidol University, Thailand \\ ${ }^{2}$ Master of Science in Nursing (Mental Health and Psychiatric Nursing), National Institute of Advanced Nursing Education (NIANER), Bangladesh \\ ${ }^{3}$ Master of Science in Nursing (Nursing Management), National Institute of Advanced Nursing Education (NIANER), Bangladesh
}

Submission: April 09, 2018; Published: April 17, 2018

*Corresponding author: Md Anwar Hossain, Nursing Officer, National Institute of Advanced Nursing Education (NIANER), Bangladesh, Email: bjnd18@gmail.com

\begin{abstract}
Breast cancer (BC) is the leading cause of illness and death for women in Bangladesh and most countries around the world. This study aimed to summarize all related evidence in regard to educational interventions to improve breast self-examination practice among women and to draw conclusions based on recommendations from evidence available at the Mahidol University electronic database/sources from 2009-2015. The search strategy followed the PICO framework as proposed by [1]. The Author's search yielded four RCTs (Level II) and four quasi-experimental studies (Level III). Breast self-examination (BSE) educational interventions was frequently delivered in various settings such as health centers, family practice clinics, health clinics, educational institutes, and semi-urban areas. Individual educational intervention should be provided for 20 minutes and group educational intervention should be managed with a range of 15 minutes to 4 hours. The number of people in the group education should not exceed 15-20 peoples. Furthermore, these interventions should be conducted by nurses, doctors, and other health care professionals. Common contents consisted of breast cancer information, risks factors, clinical features, epidemiology, early diagnosis methods, definition and importance of BSE efficiency. The outcome was measured by a questionnaire and checklist. All eight findings from the evidence supported the effectiveness of educational interventions among for improving BSE practice. It is recommended that BSE educational intervention should be taught to women to improve BSE practice to suit the clinical practice context in Bangladesh. BSE educational interventions should be further developed and applied in Bangladesh.
\end{abstract}

Keywords: Educational Intervention; Breast Self-examination Practice; Evidenced based Examination

Abbreviations: BC: Breast Cancer; BSE: Breast Self-Examination; CINAHL: Cumulative Index to Nursing and Allied Health; EBP: Evidence Based Practice

\section{Introduction}

Breast cancer (BC) is a major physical problem and fatal disease leading to high morbidity and mortality rates in both developed and developing countries. It is also the most common type of cancer in women. $\mathrm{BC}$ is a malignant tumor that starts in the cells of the breast [2]. On the other hand, BC leads to the development of psychological stress, decreased physical and sexual functioning, changes in physical image and financial problems [3]. The most common risk factor of $\mathrm{BC}$ is genetic inheritance [4] followed by age at menarche, age at menopause, age at first pregnancy, use of contraceptives, alcohol, obesity, exposure to radiation, inadequate physical activity, smoking, fatty and fried foods, all of which are predisposing factors for $\mathrm{BC}[2,4]$. BC is the most prevalent cancer and leads to mortality among women accounting for $23 \%$ of all new cancer cases and $14 \%$ of all cancer deaths in 2008 all over the world [5]. The total number of new annual BC diagnoses exceeds one million worldwide [6]. According to the American cancer society, approximately 1.3 million new BC cases were affected and 465,000 cases died from the disease [7]. Approximately 200,000 women in the United States will be diagnosed with BC every year as the disease affects one in eight American women $[4,8]$. Global cancer statistics predict the occurrence of new BC to be 1,676,600 worldwide, 793,700 in developed countries and 882, 900 in developing countries [9]. The incidence of BC has risen dramatically during the last four decades. Moreover, a growing international acceptance of western styles in sexual and reproductive practices has been associated with an increase in worldwide $\mathrm{BC}$ rates. $\mathrm{BC}$ incidence rates have been increasing in many countries such as South America, Africa and South Asia. 
In Asian countries, $\mathrm{BC}$ is the most commonly diagnosed cancer among women. In South Asia, BC is raising from 25.1 to 53.8 per $/ 100,000$ women [10]. In Iran, Thailand and Palestine more than $50 \%$ of new cases of BC in women are diagnosed at ages less than 50 years with presentation in the third and fourth stages [11]. BC remains a major challenge for health policymakers and physicians for developing countries such as Bangladesh where BC ranks first among women [12]. Bangladesh is a developing country situated in South Asia that is bordered by Burma, India and the Bay of Bengal [13] all of which share similar cultures and historic similarities. As in other South Asian countries, BC is the most common malignancy, with even greater prevalence than cervical cancer among the women in Bangladesh. A recent study showed that $21 \%$ of women were affected by BC whereby only $19.4 \%$ were affected by cervical cancer [14]. A study of the northern region of Bangladesh named Khulna Division in 2007-2008 showed that $87 \%$ of new cases of $\mathrm{BC}$ seek treatment in the third stage whereas only $4 \%$ of patients come with first and second stage BC, which are curable [13]. The presentation of third stage BC is increasing due insufficient information, inadequate knowledge about BC and screening of BC. No systematic preventive approaches are available to increase BC awareness, existing screening programs are ineffective, access to health care is limited and medical services in rural areas are poor. The aforementioned reasons might be the causes for late diagnosis of BC. Diagnostic facilities are also not readily available in Bangladesh. In Bangladesh, most $\mathrm{BC}$ occurs within the reproductive age range (15- 44 years) [10]. $\mathrm{BC}$ patients avoid treatment of the disease due to large amounts of money needed for treatment.

They do not want to disclose the disease to family members in fear of stigma or terminated relationships. Another reason for hiding the disease is financial problems because husbands or other family members have already been suffering from another disease and lost money for their treatment [13]. Therefore, most women seek treatment in the advanced stages, thereby lowering their chances for survival from this disease. In Bangladesh, over 89\% of women are Muslims [13]. Therefore, they have a tendency to hide their disease conditions in the early stages and they feel shyness and embarrassment when their breasts are examined by male doctors. BC is a severe physical condition and leads to a large number of mortalities similar to other developing countries [15]. Given the growing case burden in low and middle income countries, a large number of women are affected by the disease with excessive mortalities experienced by Bangladeshi women. For these reasons, women face many problems in the disease trajectory which affects not only the patients but also their families both physically and psychologically.

\section{Methods}

\section{Search Strategy}

The strategy employed in the search for evidence was the PICO framework with appropriate use of key words. The author

searched for evidence to improve BSE practice among women by employing the following search strategy:

Search Framework: The author searched and selected evidence for the educational intervention to improve BSE practice among women by using the PICO framework [1] with the following details:

P (Population)

I (Intervention) intervention

C (Comparison)

0 (Outcome)

Scope of the Search: The educational intervention to improve BSE practice among women was searched with the following scope:

a) Keywords used in the search according to the PICO framework.

$\mathrm{P}($ population $)=$ Women

b) Female

I $($ Intervention $)=$ Breast self-examination

c) Educational intervention Education

Teaching program

Training program

$\mathrm{C}($ Comparison $)=$ None

$\mathrm{O}$ (Outcome) = Breast self-examination practice

BSE Behavior

BSE Performance

BSE Frequency

The search used a Boolean operator. For each PICO element, the author collected any synonyms by linking terms with "OR", then located citations relevant to all the PICO elements by linking with "AND".

\section{Databases/Sources used for the Search}

The author used electronic databases/sources in the Mahidol University library system. The author searched in Blackwell Synergy, Cumulative Index to Nursing and Allied Health (CINAHL), High Wire, Ovid Full Text, Pro Quest nursing, Pub Med, Science Direct, Springer Link, and Google scholar for research studies. The author also conducted a manual search by looking for citations from reference lists and then searched further from libraries and electronic databases.

\section{Types of Evidence}

The author searched for randomized controlled trial and 
quasi-experimental studies acquired from full text studies published in English from 2009 to 2015.

\section{Appraisal Method and Levels of Evidence}

After conducting the search for evidence related to educational intervention to improve BSE practice, the author evaluates the quality and strength of evidence according to the appraisal methods and levels of evidence.

\section{Evidence Appraisal Methods}

All experimental research studies were read, analyze and synthesized for content objectives, research methodology, strength of evidence, research setting, sample group, measuring tools and findings. The evidence was appraised on the basis of the following three key questions [1]:

a) Are the results of the study valid?

b) What are the results?

c) Will the results help in caring for patients?

d) Are the results of the study valid?

The validity of a study or evidence-based practice means whether the evidence was conducted through scientific procedure and able to systematically answer the questions raised. For experimental studies, randomization is the essential step for the validity of experimental research. Some methods might produce broken allocation concealment and that might be concealed by the researcher. However, bias observation is another important step of validity analysis. Bias can arise any point of a study and alter the study to invalidate findings. Conducting blind experiments removes the bias of the research subjects (and sometimes also the researchers). Some factors potentially are affecting the outcome of the study are age, gender, social class, body mass index, and ethnicity, all of which are known as baseline characteristics. These criteria were assessed during the selection of the evidence.

\section{What are the Results?}

The result depends on accuracy, honesty, consistency, achievement and repeatability in order to determine whether or not anyone can perform the same experiment by using similar equipment and conditions to achieve exactly the same outcome. The main concerns are the extent of the effects of reported Results

\section{(Table 2)}

intervention and precisely how the effects were estimated. To appraise an experimental study, the results are credible when the findings have been tested by trials and conformed to statistically significant differences between the intervention and comparison groups. Sometimes, statistically significant differences and clinically meaningful differences are not always equivalent. However, the reliability can be assessed by intervention effects with both statistical significance and clinical significance. The reliability consists of external and internal validity.

\section{Will the Results Help in Caring for Patients?}

The target of any evidence-based research is to apply the results of patients individually or in group participation. The author can apply the results to the care of patients by asking whether the subjects in the study are similar to the patients for whom care is being delivered, whether the results are likely to be trustworthy based on the research design, whether or not the benefits outweigh the risks of treatment, whether or not the treatment is feasible for implementation in the practice setting, whether the patients who will receive the new therapy will qualify for participation in the research study. If so, it is reasonable to assume that the evidence will be applicable. The author can apply the results in the author's clinical settingwhen the benefits of patients and caregivers or families are supported by authority.

\section{Levels of Evidence}

The studies were assessed for level of evidence to evaluate the strength of the evidence. The evidence was classified into 6 levels as follows [1] (Table 1).

Table 1: Levels of evidence (Melnyk and Fineout-Overholt, 2015).

\begin{tabular}{|c|c|}
\hline Levels of evidence & Sources of empirical evidence \\
\hline Level I & Evidence from systematic reviews. \\
\hline Level II & Evidence from randomized control trials. \\
\hline Level III & Evidence from controlled cohort studies. \\
\hline Level IV & Evidence from uncontrolled cohort studies. \\
\hline Level V & $\begin{array}{c}\text { Evidence from case studies and case series, } \\
\text { qualitative and descriptive studies, Evidence- } \\
\text { Based Practice (EBP) implementation and QI } \\
\text { projects. }\end{array}$ \\
\hline Level VI & Evidence from expert opinions. \\
\hline
\end{tabular}

Table 2.

\begin{tabular}{|c|c|c|}
\hline Authors/Year/ Title & Methods/Educational intervention & Outcomes/BSE practice \\
\hline $\begin{array}{c}\text { Shahrbabaki et al.[3]. The evaluation of the } \\
\text { educational plan of breast self- examination } \\
\text { of women referring to health centers. }\end{array}$ & $\begin{array}{c}\text { This was a group educational intervention about the } \\
\text { effects of BSE education on women's knowledge and } \\
\text { performance. The program was performed by the } \\
\text { Journal of Social and Behavioral Science. } \\
\text { researcher in 2 sessions of } 20 \text { minutes for individual } \\
\text { woman in the experimental group. Booklets were } \\
\text { included as educational materials about BC, BC risk } \\
\text { factors symptoms and how they can do BSE. }\end{array}$ & $\begin{array}{c}\text { The results of the studies showed that the } \\
\text { experimental group significantly improved } \\
\text { (p }<0.001) \text { after one month of the training } \\
\text { course. }\end{array}$ \\
\hline
\end{tabular}


Kashfi et al. [2].The effect of education about breast self- examination on knowledge, attitude and practice of women in NourabadMamasami health clinics,2009. Journal of Jahrom

Gucuk et al. [19]. Effect of direct education on breast self- examination awareness and practice among women in Bolu, Turkey. Asian Pacific journal of Cancer Prevention.

Mortada et al. [21]. Effectiveness of health education intervention on improving breast self-examination among female teacher:

Applying health belief model.

The Egyptian Journal of Community Medicine.

Moustafa et al. [20].Effect of a breast-self examination educational

\begin{tabular}{l}
\hline \\
Intervention among female university \\
students. American Journal of Nursing
\end{tabular}
Science.

Moussa et al. [17]. Effect of breast selfexamination education program on knowledge, attitude and

Intervention among female university

Science.
Moussa et al. [17]. Effect of breast self-
examination education program on
knowledge, attitude and

Hay et al. [16]. Effect of educational program about breast cancer knowledge and breast self-examination training on building accurate information and behavior among

Aziz, Impact of a health education intervention program about breast cancer among women in a semi-urban area in Alexandria, Egypt. Journal of Egypt Public Health Association.
This was a group educational intervention. The BSE educational intervention was composed of 3 educational sessions and every session was conducted for 60 minutes in both groups. The education was given on $\mathrm{BC}$ and its risk factors, and BSE by using speech, question and answer, group discussions and practical demonstrations methods.

This was a group educational intervention performed by health care professional. Education provided verbally by using brochures and leaflets on the importance of breasthealth, factors causing BC, BC symptoms, the importance of BSE. The educational intervention arranged 3 independent interviews for women and the duration of the interviews varied between 15 and $45 \mathrm{~min}$.

The educational intervention consisted of 3 phases a pre-intervention phase, an intervention phase, and a post intervention phase. The education was provided on information about BC, its severity, susceptibility and how to overcome these threats by improving confidence and increasing positive believes towards early BC diagnosis methods.Educationwas given through lectures demonstrated by usingPowerPoint and group discussions. Educational tools were used such as posters, handouts, and photocopies of BSE steps, colored pamphlets, and videos.

The evidence was a group educational intervention provided by the researcher based on improving knowledge, perceptions, attitudes and practice of BSE

Before and after the intervention. The educational intervention was carried out through 4 phases. In implementation phase education given in 7 sessions lasting 30-45 minutes each group. The researcher used educational materials and various approaches to adult learning such as interactive lectures with open discussions, brainstorming, demonstration and demonstration by usingpictures, power-point presentations, booklets and mirrors, in addition to an illustrated pamphlet to enhance learning.

The evidence was an educational intervention program about BSE on nursing students' knowledge, attitude and practice provided by the researcher. The educational intervention consisted 4 phases. The education was provided on the definition of BSE.

The evidence was a group educational intervention performed by the researcher. The educational intervention was covered in 4 sessions, each session lasted 4 hours, 2 days a week for a period of 2 weeks. During the program sessions, the women were divided into two groups; each group consisted of 18 participants. Education was administered on general knowledge about BC, etiology.
The results of the study showedsignificant improvement in the intervention group knowledge, attitudes and behavior after education $(p=0.001)$ that was better than in the control group.

No statistically significant difference was found between the two groups in first and second visits. The scores for the final visit were higher for the intervention group than the control group $(\mathrm{p}<0.05)$. Scores were higher amongst women who had performed BSE prior to study enrollment at each of the three interviews $(\mathrm{p}<0.05)$.

There was significant improvement in the Health Belief Model group in terms of knowledge about BC and BSE ( $p<0.001)$. Health Belief Model subscales were used to evaluate performance of the desired behavior $(p<0.001)$ when compared to the comparison and control groups.

After implementation of the intervention, statistically significant improvements were revealed in all areas.

Knowledge $72.2 \%(\mathrm{p}<0.001)$, attitude $96.1 \%$, and practice $(\mathrm{p}<0.001)$. Therefore, the educational intervention was effective in improving students' knowledge, perceptions, attitudes, and practice.

The difference in the students' knowledge, attitude and practice were statistically highly significant $(\mathrm{p}<0.001)$ after the education program

There was statistically significant improvement in the studied women's knowledge $(\mathrm{p}<0.05)$ and practice $(83.3 \%)$ about BSE immediately after implementation of the intervention program compared to the pre- program scores

The evidence was a group educational intervention performed by the researcher. Women were divided into 6 groups; each group was composed of 15-20 women who attended 2 sessions. Each session lasted for approximately 30-45 minutes. The education was provided on breast importance and care, breast diseases/tumors and their prevalence, BC risk factors, and diagnostic methods and BSE and importance of early diagnosis by using lecture, discussion and brain storming methods. Flyers, handouts and
The results showed a highly significant improvement in the knowledge and practice from pre-to post-test $(\mathrm{p}<0.0001)$. 


\section{Discussion}

Breast cancer is escalating as a major health problem leading to high morbidity and mortality in most parts of the world $[16,17]$. In the author's clinical setting at a government hospital in Bangladesh, BC incidence has increased and become the leading cause of cancer-related deaths among women. Most of the women suffering from $\mathrm{BC}$ in Bangladesh have minimal educational background with insufficient knowledge about BC and methods of early BC detection. This problem affects patient's physical, psychological, social and economic processes. In addition, most women in Bangladesh fail to detect $\mathrm{BC}$ at an early stage due to deficient knowledge about the BC and BSE. On the other hand, there is no training program about BSE for doctors, nurses and other health care professionals in Bangladesh. The aforementioned professionals also do not use evidence-based practice (EBP) for BSE. Using evidence-based practice is essential because it integrates scientific documents, updates information, adds to clinical skills and improves patients' values [18].

For this reason, BSE practice needs to be reviewed and EBP needs to be promoted. The aim of this study was to summarize all related evidence in regard to BSE educational interventions in order to improve BSE practice among women and draw conclusions from the evidence. In order to achieve the objectives, the author searched for currently available evidence by using the Mahidol University Library electronic database systems and other websites to search for related EBP with the PICO format. The PICO framework was used to guide the keywords for the search. The keywords used were P = "women", I = "BSE educational intervention", $\mathrm{O}$ = "BSE practice". Based on the findings yielded by the search for evidence, the author obtained eight evidences on educational intervention to improve BSE practice among women. The selected eight evidences were composed of 4 RCTs (Level-II) and 4 quasi- experimental studies (Level-III). Next, the author appraised the evidence by following [1].

The appraisal was done by answering the following three key questions:

a) Are the results of the study valid?

b) What are the results?

c) Will the result help in caring for patients?

The evidence revealed BSE educational interventions to be one of the most effective methods for improving BSE practice in women. Moreover, evidence also revealed BSE educational interventions can increase knowledge, change attitudes and improve BSE practice among women. The findings confirmed that BSE educational interventions can improve BSE practice and detection of BC at an early stage. Most of the BSE educational intervention programs were performed in a health center [3], a family practice clinic [19], health clinics [2], a university and its affiliated hostel [20], a secondary school [21], a technical nursing institute [17], and a semi-urban area (Aziz et al., 2009). Although several settings are appropriate for providing BSE educational interventions, health centers at the community level are the most suitable in Bangladesh. Resources requiring BSE are available in the health center. In Bangladesh, most of the women are illiterate and live in rural areas. They do not know about BC and BSE. The BSE educational intervention at the health center in Bangladesh involves individual and group education including lectures, questions and answers, discussions and practical demonstrations about BSE for raising awareness among women. Proper BSE education and awareness may develop knowledge, attitude and behavior modification, as well as incentives to engage in regular BSE. The BSE educational intervention was performed by the researcher for effectiveness in improving BSE practice among women. However, nurses, doctors and other health care professionals were included in the programs for more effective results. One of the evidence used theory-based educational intervention such as the Health Belief Model. Most of the BSE educational interventions involved group education. Only one studies used individual educational intervention. The information was given in the BSE educational intervention by applying certain teaching strategies such as lectures, discussions, demonstrations, brainstorming, questions and answers. The majority of the studies used lecture, discussion and practical demonstration methods. Booklets, brochures, handouts, posters, power point, flipcharts, pamphlets, leaflets and videos were used as educational media. In addition, the contents commonly used in the BSE educational intervention included: - BC information, risk factors, signs and symptoms, epidemiology, the value of early diagnosis of $\mathrm{BC}$ and its methods such as CBE, mammography and BSE, prevention of BC, management strategies, definition of BSE, principles of BSE, importance of BSE, importance of breast health, position of BSE, BSE techniques, steps and best time for performing BSE. In the context of Bangladesh, BSE is the best method because mammograms are not available in rural areas and are also costly for poor people.

The sessions of the BSE educational intervention varied from 2 to 12 sessions and time duration varied from 15 minutes to 4 hours per session. The BSE educational interventions varied from 15 to 20 women per group. In most of the evidence, the researchers used self-administered questionnaires to measure knowledge, attitudes and observational checklists for assessing BSE practice in women. BSE practice was also measured by rating scales. After completing the program, posttest was completed after 4 to 6 weeks and follow up or evaluation were performed after 2 months to 3 months. All eight evidences were clearly described in terms of procedures, measuring scales, duration, time and types of education program. Most of the evidences revealed that, after using BSE educational interventions, women performed BSE practice correctly with increased frequency and number of BSE measured by the post-test and follow-up. BSE educational interventions are also effective because BSE educational interventions improve knowledge and confidence, while promoting attitude and behavior modification among women. In addition, all evidences showed a 
statistically significant increase in BSE practice among the women who received BSE educational interventions.

\section{Conclusion}

In conclusion, BSE educational interventions are important and convenient process than other costly screening methods because such interventions increase knowledge, modify attitudes and improve BSE practice among women. Moreover, BSE educational interventions are appropriate for implementation in Bangladesh because the interventions are cost effective and easily applicable with few resources and manpower. Finally, the author plans to implement BSE educational interventions to improve BSE practice among women in Bangladesh.

\section{References}

1. Melnyk BM, Fineout Overhot E (2015) Evidence-based practice in nursing \& health care: A guide to best practice. Lippincott Williams \&Wilkins, Philadelphia, USA.

2. Kashfi SM, Jeihooni AK, Yazdankhah M (2009) The effect of education about breast self-examination on knowledge, attitude, and practice of women in Nourabad Mamasami health clinics. Journal of Jahrom University of Medical Science 10(1): 36-40.

3. Shahrbabaki PM, Farokhzadian J, Hasanabadi Z, Hajjatoleslami S (2012) The evaluation of the educational plan of breast self-examination of women referring to health centers. Social and Behavioral Sciences 31 913-917.

4. Jabeen S, Haque M, Islam J, Hossain MZ, Begum A, et al. (2013) Breast cancer and some epidemiological factors: A hospital-based study. Journal of Dhaka Medical College 22(1): 61-66.

5. Ouyang YQ, Hu X (2014) The effect of breast cancer health education on the knowledge, attitude, and practice: A community health center catchment area. Journal of Cancer Education 29: 375-381.

6. Naggar RAA, Bobryshev YV, Jashamy KA (2012) Practice of breast self-examinationamong women in Malaysia. Asian Pacific Journal on CancerPrevention 13(8): 3829-3833.

7. Moodi M, Mood MB, Sharifirad GR, Shahnazi H, Sharifzadeh G (2011) Evaluation of breast self-examination program using health belief model infemale student. Journal of Research Medical Science 16(3): 316-322.

8. Schneider AP, Zainer CM, Kubat CK, Mullen NK, Windisch Ak (2014)
The breast cancer epidemic: 10 facts. The Linacre Quarterly 81(3): 244-277.

9. Torre LA, Bray F, Sigel RL, Ferlay J, Tieulent JL, et al. (2012) Global cancer statistics. Cancer Journal Clinic 65: 87-108.

10. Hossain MS, Ferdous S, Karim Kos HE (2014) Breast cancer in South Asia: A Bangladeshi perspective. The International Journal of Cancer Epidemiology Detection, and Prevention 38(5): 465-470.

11. Ahmadian M, Samah AA (2012) A literature review of factors influencing breast cancer screening in Asian countries. Life Science Journal 9(2): 585-594.

12. Rahman A, Ahsan A, Begun F, Rahman K (2015) Epidemiology risk factorsand tumor profiles of breast cancer in Bangladeshi underprivileged women. The Gulf Journal of Oncology 17: 34-42.

13. Story HL, Love RR, Salim R, Roberto AJ, Krieger L, et al. (2012) Improving outcomes from breast cancer in a low-income country:lessons from Bangladesh. International Journal of Breast Cancer, p. 1-9.

14. Nazmul HAHM, Mesbah UM, Rafiquzzaman M, Sharmin CS, Binte WT (2013) Distribution of types of cancer and patterns of cancer treatment among the cancer patient at various hospitals in Dhaka division, Bangladesh. International Research Journal 3(3): 219-222.

15. Love R (2006) Hope for breast cancer in Bangladesh.

16. Hay SAAE, Mohamed NS (2015) Effect of educational program about breast cancer knowledge and breast self-examination training on building accurate information and behavior among women. Journal of Natural Sciences Research 5(4): 58-70.

17. Moussa MMM, Shalaby NS (2014) Effect of breast self-examination education program on knowledge, attitude and practice of nursing students. International Journal of Research Studies in Bioscience 2(6): 40-49.

18. McKibbon KA (1998) Evidence-based practice. Journal of the Medical Library Association 86(3): 396-401.

19. Gucuk S, Uyeturk (2013) Effect of direct education on breast selfexamination awareness and practice among women in Bolu, Turkey. Asian Pacificjournal of Cancer Prevention 14(12): 7707-7711.

20. Moustafa DG, Allah ESA, Taha NM (2015) Effect of breast selfexamination educational intervention among female university students. American Journal of Nursing Science 4(4): 159-165.

21. Mortada, Emam M, Safie EI, Omnia S (2013) Effectiveness of health education intervention on improving breast self-examination among female teacher: Applying health belief model. The Egyptian Journal of Community Medicine 31(4): 17-40.

\section{Your next submission with Juniper Publishers will reach you the below assets}

- Quality Editorial service

- Swift Peer Review

- Reprints availability

- E-prints Service

- Manuscript Podcast for convenient understanding

- Global attainment for your research

- Manuscript accessibility in different formats

( Pdf, E-pub, Full Text, Audio)

- Unceasing customer service

Track the below URL for one-step submission https://juniperpublishers.com/online-submission.php 